\title{
CUATRO 'BOTIJUELAS' RECUPERADAS EN EL NOROESTE DE IBERIA. PROCESOS DE MANUFACTURA Y REUTILIZACIÓN
}

\author{
M. PILAR PRIETO MARTÍNEZ ${ }^{(1)}$, OSCAR LANTES SUÁREZ ${ }^{(2)}$, FRANCISCO ALONSO TOUCIDO ${ }^{(3),}{ }^{\text {LUIS }}$ \\ HIXINIO FLORES RIVAS ${ }^{(4)}$ \& MANUEL FERNÁNDEZ $\left(\right.$ LOLO) ${ }^{(5)}$
}

Resumen:

\begin{abstract}
La botijuela, "anforeta de Indias" o "olive jar" es un recipiente cerámico de época moderna y contemporánea, de distribución planetaria y vinculada originalmente al comercio marítimo ibérico, empleado como transporte de alimentos, siendo reutilizado frecuentemente y utilizado de diversas formas que no tienen relación con su uso primario. En Galicia se empiezan a documentar con cierta frecuencia estos recipientes pero todavía no se ha realizado ningún estudio sobre las mismas. En este trabajo se presentan los resultados del análisis arqueométrico de cuatro vasijas (tomografía, mineralogía y composición elemental), procedentes de colecciones particulares gallegas, tras habe realizado sobre las mismas un estudio tipológico y formal, y de cara a profundizar en su manufactura, procedencia y cronología (ésta última a partir de la comparación tipológica).
\end{abstract}

Palabras clave: Chaîne opératoire, DRX, FRX, TAC, época moderna.

Abstract:

Four 'Botijuelas' recovered in the Northwest of Iberia. Processes of manufacture and reuse

The "anforeta de Indias", "botijuela" or "olive jar" is a ceramic container of modern and contemporary period, of planetary distribution and linked originally to the Iberian maritime trade, to transport foods. These items were recycled frequently and used with no relation with his primary use. In Galicia these containers are documented frequently but vessels (tomography, mineralogy and elementary composition), after having made on the same a typological and formal study, to deep on his manufacture, chronology and origin.

keywords: Chaîne opératoire, DRX, FRX, TAC, Early modern period.

\section{INTRODUCCIÓN}

La investigación en cerámicas de época postmedieval en Galicia está pendiente de desarrollarse. Algunos estudios puntuales sobre cerámica de lujo moderna han ido publicándose en los últimos años (i.e. Martínez 2013, SuÁrez 1993, Caramés 2006, CARAmÉs et al. 2006, CASTro 2006 y 2009, Prieto et al. 2015, Prieto et al. 2017). Excepcionalmente está empezando a ser de interés la alfarería tradicional (LANTES-SuÁrez et al. 2016; LANTES SUÁREZ 2018). Ahora mostramos por primera vez un estudio con un enfoque integrado arqueológico $\mathrm{y}$ arqueométrico de un conjunto de cerámicas de transporte denominadas 'anforeta de indias'. La anforeta de Indias, "botijuela" o también denominada en inglés "Olive Jar" (GoGGIN 1960), son contenedores conocidos entre el siglo XV y XIX, empleadas no sólo en las áreas de fabricación en Europa sino también utilizadas como contenedores de transporte naval a otros continentes. Son bien conocidas las piezas de numerosos pecios de sitios costeros coloniales españoles y británicos así como en naufragios españoles y portugueses (CARTER 1982). Los hallazgos más sistemáticamente estudiados son los encontrados en las costas americanas, resultado de las transacciones comerciales con las Américas, las Indias y Asia.

El origen de las piezas se plantea en Andalucía (GogGin 1960: 5), entre el área de Sevilla (Pleguezuelo y Lafuente 1995: 234) y la gaditana (PEACOCK \& Williams 1986: 29-30) pero ante todo centrada en el valle del Guadalquivir dado que la composición de sus pastas son idénticas a las ánforas romanas Dressel 20 (Costa et al. 2011). Debido a que la Casa de la Contratación en Sevilla (desde 1503) y Cádiz (desde 1720 por Real Cédula) tenían el monopolio del comercio transatlántico, se cree que se fabricarían próximas a los puertos de partida para cargar los barcos españoles. Diferentes oficinas podrían existir en Andalucía, aunque no se puede dejar de mencionar la existencia de dos centros de producción en Triana (Sevilla) con ocho talleres alfareros que en el siglo XVI fabricaban anforetas, a partir de información del Archivo de Indias (MARKEN 1994: 46-7). Los análisis arqueo-

\footnotetext{
${ }^{(1)}$ Grupo de Investigación ES2, Universidad de Santiago de Compostela. E-mail: pilar.prieto@usc.es. Cod. ORCID: 0000-0002-5152-6307

${ }^{(2)}$ Unidade de Arqueometría. RIAIDT. Universidade de Santiago de Compostela. e-mail: oscar.lantes@usc.es. Cod ORCID: 0000-0003-1987-9759

(3) Grupo de Investigación Síncrisis, Universidad de Santiago de Compostela. E-mail: franalonsotoucido@hotmail.com Cod. ORCID: 0000-0003-2554-5448

(4) Fotógrafo etnográfico, Lugo, hixinioflores@gmail.com

${ }^{(5)}$ Ceramista en Anseán, Corgo, Lugo, lolodavila@hotmail.es
} 
métricos recientes confirman la existencia de dos industrias sevillanas durante los ss. XV y XVI, una relacionada con la tradición mudéjar musulmana, y la otra con la industria de majólica de Triana (GómEZ Ferrer et al. 2013: 15). Ambas industrias son similares a las encontradas en el pecio de Red Bay del siglo XVI en el Golfo De Saint Lawrence, Canada, el tipo RB1 (anforeta de forma globular), para transportar y almacenar (ESCRIBANO \& BARREIRO 2016: 33).

Con el relajamiento de las leyes comerciales españolas en el siglo XVIII, sin embargo, las vasijas del período tardío podrían haberse fabricado en otros centros en el norte y este de España cuando otros puertos se vieron atraídos al comercio transatlántico y Atlántico oriental (GoGGIN 1960, CARTER 1982). Por Real Decreto en 1765 se franquean al comercio colonial otros puertos como Santander, Gijón, Málaga, Cartagena, Alicante, Santa Cruz de Tenerife, Almería, Torosa, A Coruña (LóPEz 1980: 150). En Portugal, Aveiro, es un centro aceptado como productor de este tipo de cerámica (COSTEIRA DA SiLva 2018), y Lisboa también se apunta como posible centro productor pues es un punto de paso obligatorio (LOUREIRO \& MARTINHO 2007), muestra de ello podrían ser las anforetas encontradas en el pecio Santo António de Tanna y las de Cabo Sardâo que, en ocasiones, difieren de las españolas (LOUREIRO \& MARTINHO 2007: 406), incluso podrían haber sido fabricadas en otras zonas como Sudamérica, dado que se constata una variación en la composición de las pastas cerámicas dejando de estar estandarizadas como en las primeras fases de la producción (CARrouthers 2003), como es el caso de Panamá donde se ha encontrado material anfórico de manufactura local (FERRER et al. 2015).

Aunque la función de estas vasijas es el transporte de alimentos, se muestra como un tipo multifuncional desde sus inicios, como bien recoge Carter (1982) que se reutiliza para diferentes usos (LoUREIRO Y MARTINHO 2007: 405), una de sus funciones principales era contener aceite de oliva, aceitunas en salmuera, vino y otros alimentos (GogGin 1960). Ha sido establecido que como parte del comercio trasatlántico a bordo de los buques españoles, la forma $\mathrm{A}$ de estas botijas se utilizaba para transportar vino (MARKEN 1994), mientras que la forma B era utilizada para el transporte de aceite de oliva (MARKEN 1994, COLIN MARTIN 1997) o aguardiente (Escríbano \& Mederos 1998: 549) y la C para el acarreo de miel (MARTIN 1997). Sin embargo, pueden haber tenido usos secundarios igualmente importantes como enfriadores de agua (WATKINS 1972) y material de construcción de edificios (GogGIN 1960), en tejados de casas e iglesias sobre vigas del techo en Caribe, República Dominicana, Cuba, Puerto Rico (GoGGIN 1964: 257) o paredes completas en México (Marken 1994: 46), incluso llega a reutilizarse como instrumento musical en $\mathrm{Cuba}^{1}$, o como linternas navales para iluminación nocturna
(AZKARATE \& NúÑEZ 1990/91:165).

Loureiro y Martinho (2007: 379) realizan una síntesis de las funciones de las botijuelas a partir de los autores más destacados en su estudio (MARKEN 1994, GogGin 1960, Avery 1993). Gradualmente estas botijuelas se están dejando de ver como meros contenedores cerámicos y empiezan a ser estudiadas como un elemento que ayuda comprender mejor las redes comerciales del siglo XV al siglo XIX (LOUREIRO \& MARTINHO 2007).

Un par de trabajos han sido pioneros en Galicia sobre anforetas (FARIÑA et al. 1973, LOPEZ 1980) y un mapa de distribución fue realizado en los años ochenta del siglo pasado para la Península Ibérica (BENITO 1987).

Hoy en día la tipología de Goggin (1960), aunque con algunas matizaciones cronológicas, sigue funcionando y continúa siendo utilizada por buena parte de los investigadores.

Las primeras botijuelas documentadas en Galicia fueron interpretadas como romanas, pero pronto se aclaró la cronología general de las mismas (FARIÑA et al. 1973, LóPEZ 1980). Los principales contextos de aparición en Galicia son tres. En primer lugar, excavaciones terrestres, en las que aparece muy fragmentada, tanto en intervenciones próximas a la costa como el castillo de Lúa, en Rianxo (CÉSAR \& BonILla 2003), o en el interior como en el castillo de Rocha Forte (Martínez, 2006, 2007) en Santiago de Compostela. Asimismo, puede ser encontrada en el interior de violaciones de túmulos megalíticos, resultado de su abandono, tras haberse realizado la búsqueda de tesoros (por ejemplo, Monte da Romea ${ }^{2}$ o Roza das Aveas, -PRIETO et al. 2010). Son habitualmente piezas muy fragmentadas que pasan a formar parte del inventario sin mayor estudio en profundidad. En segundo lugar, debemos destacar las documentadas en intervenciones de índole subacuática, donde su conservación suele ser óptima, o incluso en playas traídas desde los fondos marinos por la acción del mar. Podemos destacar por ejemplo el pecio de Ribadeo (SAN Claudio et al. 2014). En este caso, dado su estado de conservación, suelen ser las piezas más abundantes en las colecciones visitables de los museos.

Finalmente, estas anforetas, son empleadas con objetivo decorativo y funcional en el remate tradicional de tejados (casas y hórreos), principalmente en la zona de la Mariña lucense y occidente asturiano. Fueron documentadas en los años 80 en otros puntos como el Ulla o la comarca do Morrazo, pero su uso ya no se detecta, al contrario que en la Mariña lucense (LóPEZ 1980). En el occidente asturiano son también comunes en la actualidad (DíAz 2016). También es frecuente encontrarlas formando parte de colecciones particulares adquiridas por herencia familiar o en tiendas de compraventa de antigüedades. Algunas de las anforetas utilizadas como remate arquitectónico están rellenas de material constructivo como morteros o ce-

\footnotetext{
${ }^{(1)} \mathrm{http}: / /$ fidelseyeglasses.blogspot.com/2009/02/la-botijuela-el-bombardino-el.html, consultado el 7 julio 2018 .

(2) Probablemente la pieza interpretada como ánfora romana, sea una 'botijuela', pues aparece en los mismos contextos de revuelto que la cerámica olla de época moderna (Prieto 2007).
} 
mento, con el objetivo de servir como cementante y además dotarlas de peso, así cumplen no solo una función decorativa si no que aportan consistencia estructural al propio tejado, siendo su punto de remate final, sin el cual el tejado se encontraría inconcluso.

A continuación se presenta el estudio realizado sobre cuatro ejemplares, a los que hemos podido tener acceso y permiso para su análisis, procedentes del noroeste peninsular, conservando uno de ellos mortero en su interior. Después de su estudio tipológico y formal, se realizó un registro tomográfico y se analizó la composición mineralógica y elemental de sus pastas, además del vidriado en alguna de ellas.

El principal objetivo del estudio es profundizar en el conocimiento de su cronología y procedencia. A pesar de ser piezas sin contextualizar, al encontrarse completas, es más fácil identificarlas formalmente, facilitando asimismo la localización de los talleres de procedencia, al contrario de lo que sucede en las piezas recuperadas en los contextos arqueológicos terrestres, en donde a menudo por lo fragmentadas que aparecen estas piezas no llegan a ser ni siquiera identificadas. Por ello, y a pesar de su falta de contexto, este estudio puede ser de utilidad como primer paso para caracterizar un tipo de pieza en nuestra región, que además es frecuentemente reutilizada como elemento arquitectónico en el noroeste ibérico.

\section{EL CONTEXTO DE LAS PIEZAS}

Si nos centramos en las piezas estudiadas, su contexto es incierto, pues se desconoce el yacimiento o yacimientos de los que procede, formando parte de colecciones particulares. La anforeta LOL01 (Fig. 2) pertenece a la colección particular del ceramista y coleccionista Manuel Fernández López desde la década de los 80, la cual fue adquirida en mercado de coleccionismo en Sarria en esas fechas. La botijuela LOL02 (Fig. 1), pertenece al mismo coleccionista y fue comprada en un anticuario de Navia, en Asturias. Su vendedor le informó que se encontró en la costa en el entorno de esta población. Las otras dos anforetas, pertenecen a la colección particular de Hixinio Flores Rivas. En el caso de la anforeta HIX01 (Fig. 4), procede de una herencia familiar. En concreto, la pieza residió durante buena parte del siglo XX en una casa del ayuntamiento de A Pontenova (Lugo), cercano a la costa y en la frontera con Asturias, si bien, no se puede asegurar cuando llegó allí. Unicamente se sabe que tuvo un uso secundaro constructivo, delatado por el relleno de mortero de su interior. Finalmente la cuarta anforeta, HIX02 (Fig. 3), es fruto de una cesión a este coleccionista que se realizó en Lugo a inicios del s. XXI, el antiguo propietario la compró en un anticuario de Sarria, que a su vez fue comprada a otro anticuario de O Incio (ayuntamiento de Lugo), en aquella época. Dado que este anticuario tenía más anforetas que procedían de Navia en Asturias, se sospecha que este pudo ser su lugar de origen.

\section{METODOLOGÍA}

El estudio arqueológico se basa en la caracterización macroscópica del material que permite la reconstrucción de la cadena operativa de las piezas, seguimos el enfoque empleado para la cerámica antigua de la región (Prieto et al. 2018). Para observar la pieza en su interior se complementó el examen macroscópico externo con el estudio tomográfico (Figs. 1-5).

El estudio tomográfico de rayos $\mathrm{X}$ se realiza en los cuatro recipientes y permite observar la pieza en su interior de un modo no destructivo (LANTES \& Prieto 2017a, 2017b). El equipo utilizado es un TAC multicorte Hitachi Eclos CT con resolución de voxel de décima de milímetro, estación de procesado y software de procesado y análisis de imagen. El producto que se obtiene es la reconstrucción tridimensional externa e interna de los recipientes que se puede visualizar en tomogramas (formato DICOM) y realizar determinaciones cuantitativas sobre las mismas. Los motivos más densos, como el desgrasante o vidriados son más radiodensos (se visualizan con colores más claros) y los motivos menos densos como residuos orgánicos o el aire son muy poco radiodensos (se visualizan con colores más oscuros). Para el procesado de las imágenes se utiliza el software RadiAnt DICOM (https://www.radiantviewer.com/).

Para los análisis de composición de pastas y relleno (éste en HIX01) se realizaron muestreos con un micromotor con fresa de punta de polvo de diamante. Las muestras de cuerpo cerámico se recogieron en zonas próximas a roturas o en partes desapercibidas del objeto, para intentar que fuese lo menos invasivo posible.

La mineralogía se identificó a través de la técnica de difracción de rayos $\mathrm{X}$ de polvo cristalino utilizando un difractómetro Philips PW1710 con goniómetro vertical de geometría Bragg-Brentano $\theta / 2 \theta$, generador con tubo de $2,2 \mathrm{Kw}$ con ánodo de $\mathrm{Cu}$ monocromador de grafito y detector proporcional PW1711/10, con un tiempo de medida de 3 segundos por paso en un rango angular de 2 a $65^{\circ}$ de $2 \theta$. Para la semicuantificación se utiliza el sowtware DIFFRACplus EVA, de Bruker AXS.

La FRX se realiza con dos espectrómetros de fluorescencia de rayos X de emisión de energía. Constan de un generador de rayos $\mathrm{X}$ con ánodos primarios de molibdeno y plata (éste con ánodos secundarios de pirografito y hierro acoplados). Los detectores multielementales son semiconductores de $\mathrm{Si}(\mathrm{Li})$ refrigerados en N2(1). Se determinan con ánodo secundario de pirografito los elementos químicos $\mathrm{Mg}, \mathrm{Al}, \mathrm{Si}, \mathrm{P}, \mathrm{S}$ y $\mathrm{Cl}$, con el ánodo secundario de hierro los elementos $\mathrm{K}, \mathrm{Ca}, \mathrm{Ti}, \mathrm{V}$ y $\mathrm{Cr}$ y para el resto de elementos -de Mn a U- se usa un ánodo de molibdeno. El tiempo de medida oscila entre 5 a 10 minutos. Para la cuantificación de las concentraciones se realizaron calibraciones previas con geomateriales de referencia certificados (NIST).

La botijuela LOL02 posee un vidriado parcial que se micromuestreó para su análisis, asimismo se estudió su morfología y composición elemental en microscopía electrónica de barrido acoplada con 
M. Pilar Prieto Martínez, Oscar Lantes Suárez, Francisco Alonso Toucido, Luis Hixinio Flores Rivas \& Manuel Fernández (Lolo)

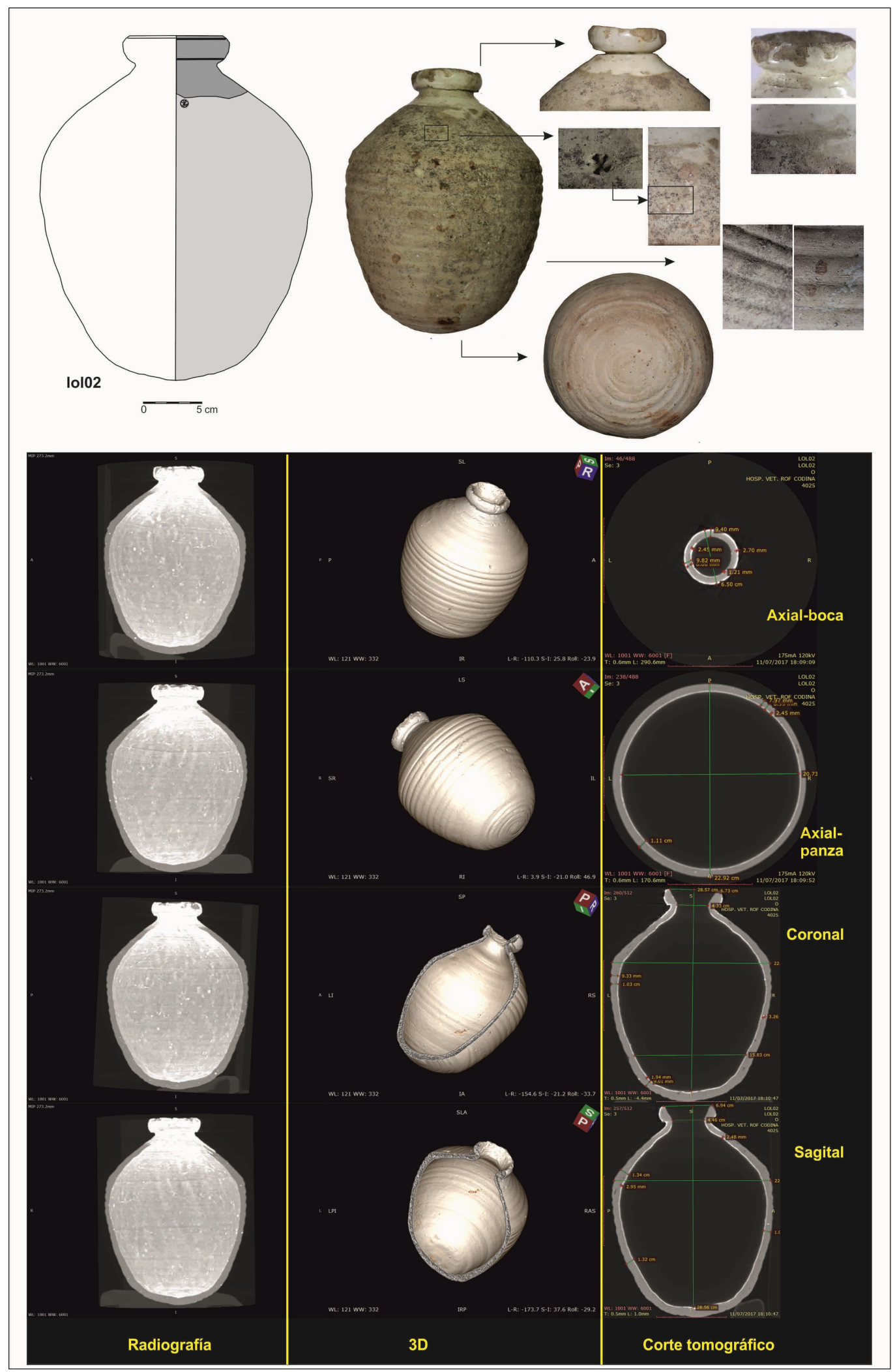

Fig. 1. Botijuela globular LOL02: dibujo, fotografías y vistas topográficas diversas (radiografía, 3D y cortes tomográficos). 


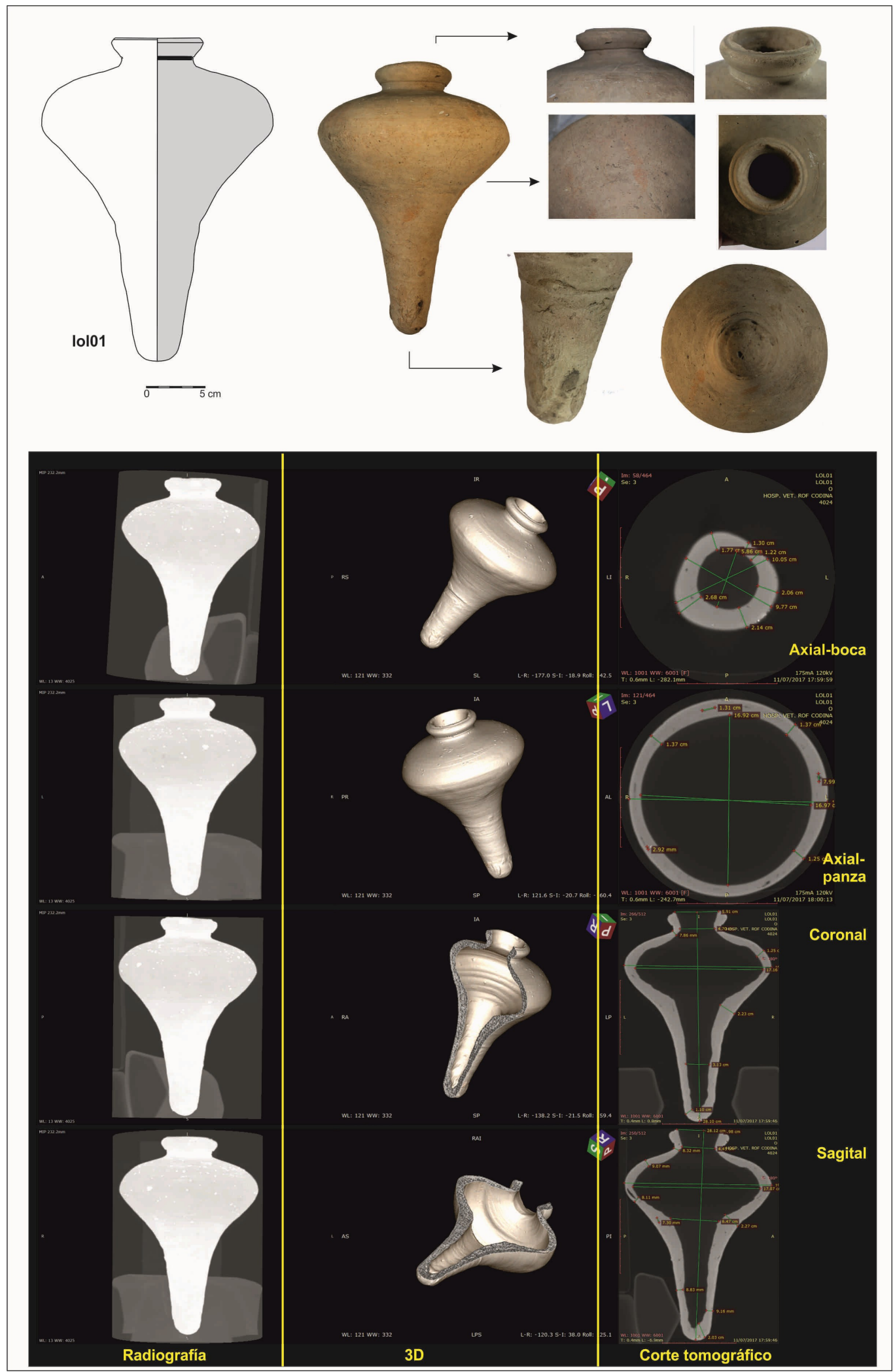

Fig. 2. Botijuela piriforme LOL01: dibujo, fotografías y vistas topográficas diversas (radiografía, 3D y cortes tomográficos). 
M. Pilar Prieto Martínez, Oscar Lantes Suárez, Francisco Alonso Toucido, Luis Hixinio Flores Rivas \& Manuel Fernández (Lolo)

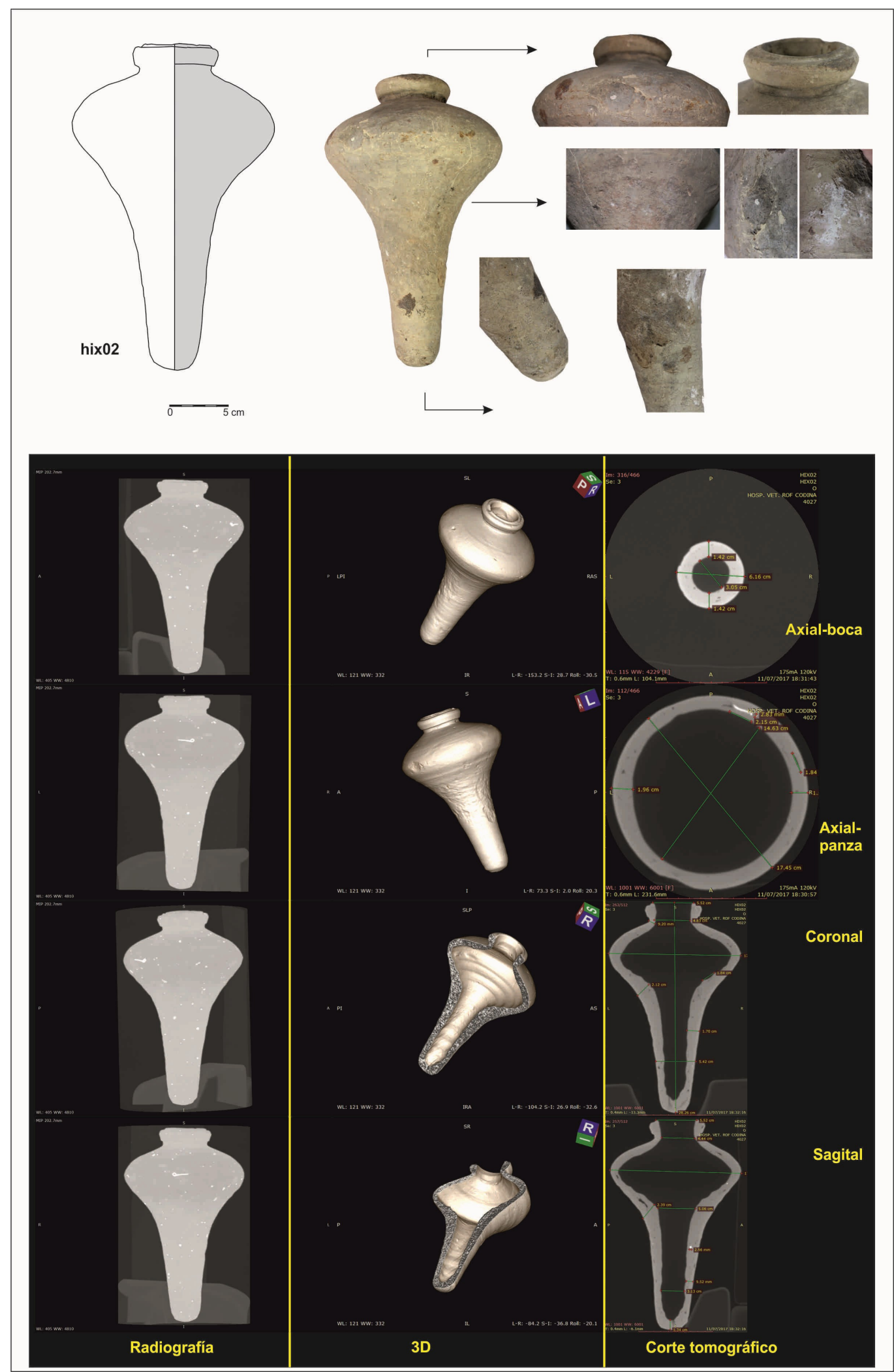

Fig. 3. Botijuela piriforme HIX02: dibujo, fotografías y vistas topográficas diversas (radiografía, 3D y cortes tomográficos). 


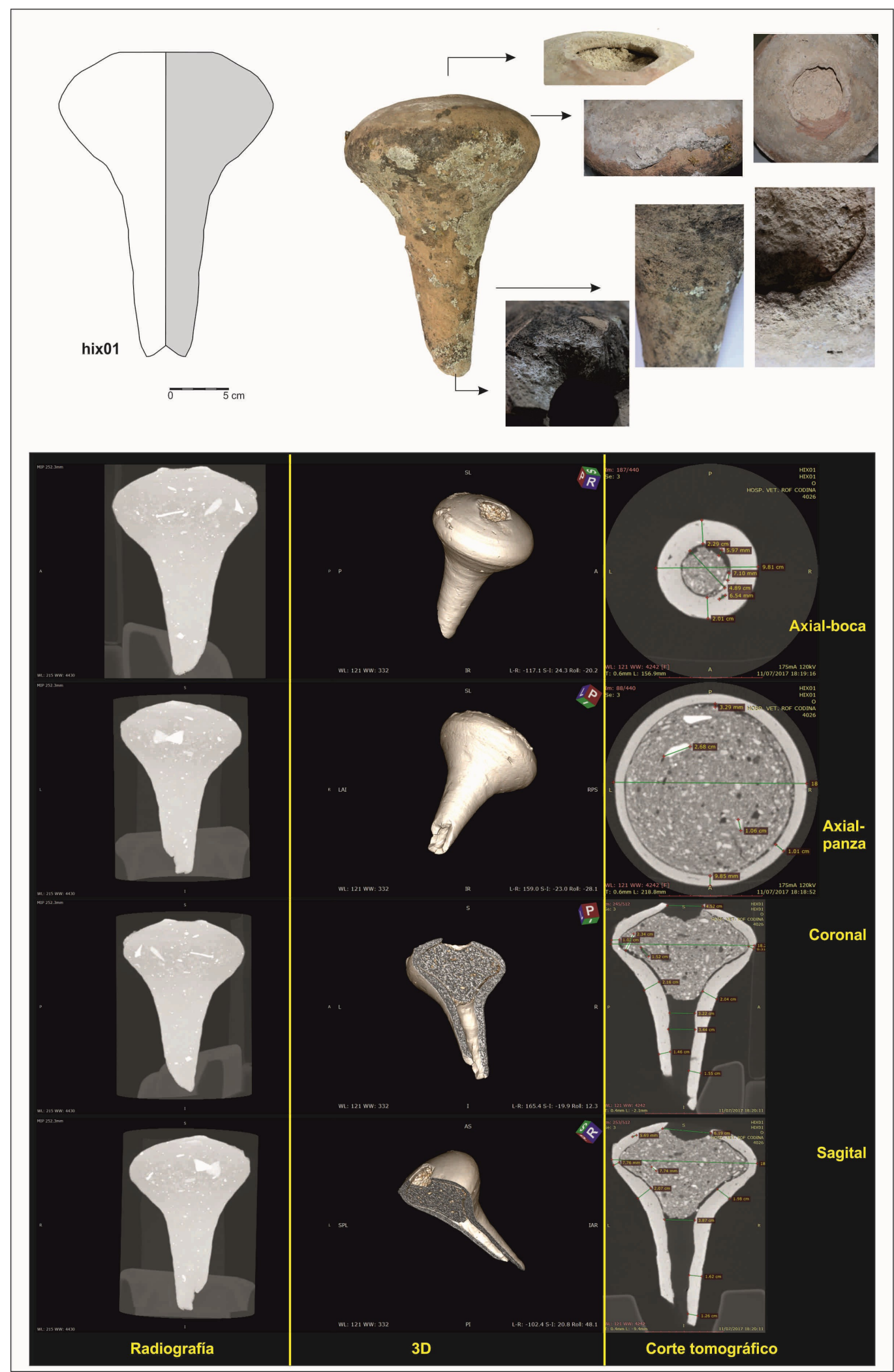

Fig. 4. Botijuela piriforme HIX01: dibujo, fotografías y vistas topográficas diversas (radiografía, 3D y cortes tomográficos). 


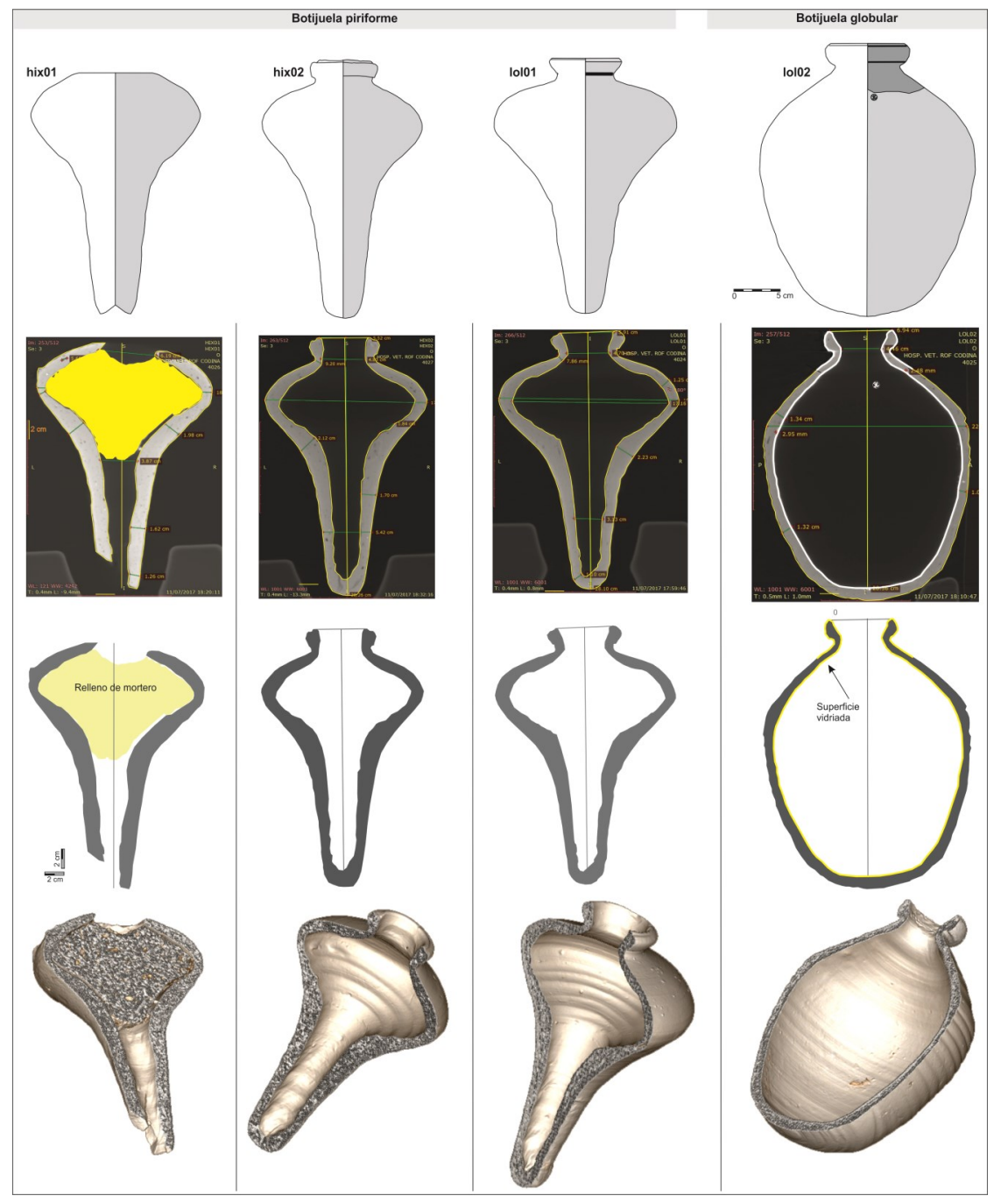

Fig. 5. Fases del trabajo gráfico, desde el dibujo inicial (1), pasando por la tomografía retocada con dibujo a escala (2), extracción de secciones dibujadas (3) y la reconstrucción 3D de una sección de las piezas(4).

una microsonda de rayos X (SEM-EDX) según Lantes et al. (2011). Los resultados arqueológicos y arqueométricos se comparan para intentar identificar si hay semejanzas o diferencias entre las piezas para poder valorar así procedencias comunes.

Además, en el caso de la botijuela piriforme HIX01, que estaba rellena de mortero, se recogió una muestra del mismo para analizar.

\section{RESULTADOS}

\subsection{Caracterización formal}

Las vasijas son contenedores de dos tipos, uno de cuerpo globular (LOL02) y tres de cuerpo piriforme (Tabla 1). Las características morfológicas son las que guiarán el orden de la descripción que realizaremos seguidamente, sin tener en cuenta los códigos de las piezas, dato meramente identificativo. Así que comenzaremos por la botijuela globular, y finalizaremos con la anforeta piriforme (HIX01) que posee un relleno interior.
La botijuela LOL02 (Fig. 1) es de cuerpo globular y perfil simétrico y regular de labio apuntado (forma tipo B de la fase Media y Reciente de Goggin 1960), semejante a las encontradas en el puerto de A Coruña (LóPEz 1980, figs. 27 y 28). Es la vasija de mayor tamaño, pues posee una altura de $300 \mathrm{~mm}$ y mayor capacidad de 5,9 litros (equivale aproximadamente a la botija de media arroba o media perulera, de 5,7 litros, 11,5 pintas). El recipiente podría haber sido fabricado en 3 partes, pues se aprecian diferencias fuertes entre los acabados de dichas partes: (1) el tercio superior con un alisado que disimula las marcas de torno, (2) el cuerpo (marcas de torno más desarrolladas y más resaltadas en la superficie exterior que la interior con $1 \mathrm{~cm}$ de anchura), y (3) la base probablemente fue sumada al cuerpo, también tiene unas marcas de torno resaltadas. Las paredes de la botijuela son regulares y homogéneas rondan el centímetro de anchura (13-10 $\mathrm{mm}$ ). Presenta un peso de 3,3 kg. Las pastas de esta botijuela son compactas finas y color beige, con un desgrasante inapreciable de caliza y posi- 
ble cuarzo, cuyo tamaño superficial es inapreciable de visu. A partir de la tomografía, se observa una densidad que parece regular en todo el cuerpo del recipiente, si bien hay abundantes poros, éstos son pequeños $(2-3 \mathrm{~mm})$ y están distribuidos de forma regular. Son apreciables algunas rebabas exteriores y desconchados de burbujas resultado de una manufactura apurada. Finalmente, en general su estado de conservación es bueno, aunque se observan desconchados, manchas de oxidación y manchas negruzcas consecuencia de su deposición en un ambiente húmedo y sucio.

Asimismo, posee un vidriado parcial en el exterior que cubre la boca, cuello e inicio de la panza de color blanco cremoso (asociado con las botijuelas B tardías de Goggin, de 6,3 litros). Gracias al TAC se ha podido comprobar que el vidriado cubre la totalidad de la superficie de la pieza en su interior siendo su grosor de 2,48 a $2,95 \mathrm{~mm}$, semejante al exterior $(2,70 \mathrm{~mm})$.

Esta pieza tiene una huella de alfarero que consiste en una marca pequeña impresa de una especie de cruz dentro de un círculo de $1 \mathrm{~cm}$ de diámetro aplicado antes de la cocción. Se localiza justo en el punto de transición entre el hombro y la panza, en una zona no vidriada.

Esta forma se asemeja a la del estilo tardío B de Goggin que Carrouthers (2003) adelanta la fecha

Tabla 1. Descripción de los diferentes rasgos morfotécnicos de las botijuelas

Morfología
\begin{tabular}{|l|l|l|l|l|l|l|l|l|l|}
\hline Código & $\begin{array}{l}\text { Adscripción } \\
\text { Cultural }\end{array}$ & Categoría & $\begin{array}{l}\text { Morfología } \\
\text { global }\end{array}$ & Perfil & Borde & Labio & Cuello & Panza \\
\hline LOL02 & Edad Moderna & Botijuela & $\begin{array}{l}\text { Compuesta } \\
\text { cerrada }\end{array}$ & Globular & Vertical & Apuntado & $\begin{array}{l}\text { Corto y muy } \\
\text { estrangulado }\end{array}$ & $\begin{array}{l}\text { Globular con } \\
\text { hombro superior }\end{array}$ & Globular \\
\hline LOL01 & Edad Moderna & Botijuela & $\begin{array}{l}\text { Compuesta } \\
\text { cerrada }\end{array}$ & $\begin{array}{l}\text { Piriforme o } \\
\text { apuntada }\end{array}$ & Vertical & Biselado & $\begin{array}{l}\text { Corto y muy } \\
\text { estrangulado }\end{array}$ & Esfera aplastada & Pitorro \\
\hline HIX02 & Edad Moderna & Botijuela & $\begin{array}{l}\text { Compuesta } \\
\text { cerrada }\end{array}$ & $\begin{array}{l}\text { Piriforme o } \\
\text { apuntada }\end{array}$ & Vertical & Biselado & $\begin{array}{l}\text { Corto y muy } \\
\text { estrangulado }\end{array}$ & Esfera aplastada & Pitorro \\
\hline HIX01 & Edad Moderna & Botijuela & $\begin{array}{l}\text { Compuesta } \\
\text { cerrada }\end{array}$ & $\begin{array}{l}\text { Piriforme o } \\
\text { apuntada }\end{array}$ & No conserva & No conserva & $\begin{array}{l}\text { Corto y muy } \\
\text { estrangulado }\end{array}$ & Esfera aplastada & Pitorro \\
\hline
\end{tabular}

\section{Diámetros (mm)}

\begin{tabular}{|l|l|l|l|l|l|l|l|l|l|}
\hline Código & d. boca & d. cuello & d. panza & d. fondo & altura & Litros & Perfil & Altura \\
\hline LOL02 & 74 & 64 & 230 & 120 & 300 & 5,9 & Regular & Regular & Si \\
\hline LOL01 & 76 & 60 & 200 & 36 & 284 & 1,45 & Asimétrico & Irregular & Si \\
\hline HIX02 & 74 & 62 & 176 & 40 & 285 & 1,075 & Asimétrico & Irregular & Si \\
\hline HIX01 & no conserva & 80 & 184 & 42 & 270 & no se sabe & Asimétrico & Irregular & Si \\
\hline
\end{tabular}

Anchura de la fractura (mm)

\begin{tabular}{|l|l|l|l|l|l|l|l|l|l|}
\hline Código & ancho boca & $\begin{array}{l}\text { ancho } \\
\text { cuello }\end{array}$ & $\begin{array}{l}\text { ancho panza } \\
\text { sup. }\end{array}$ & $\begin{array}{l}\text { ancho panza } \\
\text { centro }\end{array}$ & $\begin{array}{l}\text { ancho panza } \\
\text { inf. }\end{array}$ & ancho base & $\begin{array}{l}\text { pared hacia } \\
\text { base }\end{array}$ & Peso gramos \\
\hline LOL02 & 10 & 5 & 13,4 & 9,33 & 13,2 & 9,2 & & 3300 & bueno \\
servación con-
\end{tabular}

Pastas

\begin{tabular}{|c|c|c|c|c|c|c|c|c|c|c|}
\hline Código & Acabado ext. & Calidad ext & Acabado int & $\begin{array}{l}\text { Coloración } \\
\text { pasta ext }\end{array}$ & Técnicas fab & Desg Grosor & Desg Cantidad & $\begin{array}{l}\text { Desg Distribu- } \\
\text { cion }\end{array}$ & Textura & $\begin{array}{l}\text { Tipo } \\
\text { desgrasante }\end{array}$ \\
\hline LOL02 & $\begin{array}{l}\text { Torneado y } \\
\text { semividriado }\end{array}$ & Tosca & Vidriado & Beige & Torno & Inapreciable & Escasa & Irregular & Compacta & $\begin{array}{l}\text { Caliza y } \\
\text { posible } \\
\text { cuarzo }\end{array}$ \\
\hline LOL01 & $\begin{array}{l}\text { Torneado y } \\
\text { alisado }\end{array}$ & Medio & Torneado & Beige & Torno & Inapreciable & Escasa & Irregular & Compacta & $\begin{array}{l}\text { Caliza y } \\
\text { posible } \\
\text { cuarzo }\end{array}$ \\
\hline HIX02 & Torneado & Medio & Torneado & Beige & Torno & $2 \mathrm{~mm}$ & Escasa & Irregular & Compacta & $\begin{array}{l}\text { Caliza y } \\
\text { posible } \\
\text { cuarzo }\end{array}$ \\
\hline HIX01 & Torneado & Medio & Torneado & Beige rosado & Torno & Inapreciable & Escasa & Irregular & Muy Compacta & Inapreciable \\
\hline
\end{tabular}

Huellas
\begin{tabular}{|l|l|l|l|l|l|l|}
\hline Código & Oxidación & Burbujas & $\begin{array}{l}\text { Desconcha- } \\
\text { dos }\end{array}$ & Rebabas & Digitaciones & Mortero int. \\
\hline LOL02 & Sí & Sí & Sí & Sí & & \\
\hline LOL01 & & & & Sí & & \\
\hline HIX02 & Sí & & Sí & Sí & Sí & \\
\hline HIX01 & & & & & & Sí \\
\hline
\end{tabular}


al 1773 a partir de los contextos del monasterio de Santo Domingo en La Antigua Guatemala (y no a 1780 como valora Goggin en su tipología). Se pasa de poner las marcas de alfarero en el borde de las piezas a ponerlas en el hombro hacia el tercer cuarto del siglo XVIII en el monasterio de Guatemala (CARrouthers 2003).

La botijuela LOL01 (Fig. 2) es de cuerpo piriforme de labio biselado (forma tipo $\mathrm{D}$ de la fase Reciente de GogGIN 1960). El cuerpo es muy asimétrico e irregular. Posee una altura de $284 \mathrm{~mm}$ y una capacidad de 1,45 litros, casi medio litro más que la pieza HIX02, pues posee una panza con un diámetro mucho mayor. El recipiente podría haber sido fabricado en 3 partes por los cambios bruscos de forma: (1) borde, (2) panza con unas marcas de torno más desarrolladas, y (3) el pivote prolongado. Las paredes de la botijuela son extremadamente irregulares con grosores que varían desde los $8 \mathrm{~mm}$ hasta los $23 \mathrm{~mm}$ de grosor en la panza. Presenta un peso de $2,139 \mathrm{~kg}$.

Se identifican huellas de torno que parecen haber sido regularizadas en la superficie exterior, siendo muy marcadas en el interior. Las pastas son compactas, de color beige y con un desgrasante de muy reducido tamaño de caliza y posible cuarzo en superficie. A partir de la tomografía se observa que el mayor grosor de pared se encuentra en la panza así como los desgrasantes más evidentes (de forma alargada en vertical y horizontal, localizados en el corte del centro de la panza, algunas burbujas alcanzan $20 \mathrm{~mm}$ ). En general su estado de conservación es bueno, aunque presenta abundantes rebabas horizontales en la zona de la base y algún resto de oxidación, de escasa entidad.

La anforeta HIX02 (Fig. 3) de cuerpo piriforme de labio biselado (forma tipo D de la fase Reciente de Goggin 1960) semejante a las encontradas en el puerto de A Coruña (LóPEZ 1980, fig 24). El cuerpo es muy asimétrico e irregular. Posee una altura de $285 \mathrm{~mm}$ y una capacidad de 1,07 litros. El recipiente podría haber sido fabricado, como el anterior, en 3 partes. Las paredes de la botijuela son, como la anterior, extremadamente irregulares con grosores que varían desde los $9 \mathrm{~mm}$ hasta los $23 \mathrm{~mm}$ de grosor en la panza, con variaciones parecidas a la pieza anterior. Presenta un peso de 1,879 $\mathrm{kg}$, próximo al anterior. Se documentan en el mismo huellas de torno que parecen haber sido regularizadas en superficie, unas pastas compactas y color beige y se percibe algún desgrasante disperso que puede alcanzar los $2 \mathrm{~mm}$ de tamaño de caliza y posible cuarzo. A partir de la tomografía se aprecia una densidad homogénea en todo el cuerpo del recipiente, si bien los desgrasantes son semejantes a la pieza anterior (de forma alargada en vertical y horizontal, localizados en el corte del centro de la panza, algunas burbujas alcanzan $20 \mathrm{~mm}$ ).

En la superficie de la botijuela se registran óxidos dispersos por la superficie, al igual que burbujas, digitaciones en la superficie exterior y rebabas, todo ello parece el resultado de una fabricación apurada, típica de una producción en serie de recipientes de almacenamiento, despensa o transporte, donde lo importante no es la estética del mismo sino la funcionalidad. Presenta asimismo un amplio desconchado en la parte inferior de la panza, donde se estrecha hacia la base, muy apreciable a través de la reconstrucción en 3D de la tomografía.

La anforeta HIX01 (Fig. 4) de cuerpo piriforme (forma tipo D de la fase Reciente de Goggin 1960), que ha sido remodelada, extrayéndose la parte superior de la pieza (borde-cuello), así que la pieza comienza justo en el inicio de la panza, por lo que es la pieza de conservación más deficiente. No se pudo calcular su capacidad, dado que en su interior presenta un relleno de mortero, probablemente con el objetivo de aumentar su peso y que sirviera para facilitar su fijación como adorno de tejado. Aun así, las proporciones de su cuerpo concuerdan con las otras dos anforetas del conjunto, en general de cuerpo asimétrico. Presenta huellas de torno que parecen haber sido regularizadas en superficie, unas pastas muy compactas, duras y color beige rosado. Presenta un peso de $3,6 \mathrm{~kg}$, sin embargo este peso se corresponde a la pieza completa, arcilla y relleno de mortero. Teniendo en cuenta el peso de las otras anforetas piriformes, probablemente en torno a 1,5 $\mathrm{kg}$ se corresponde con el peso del mortero interno.La textura de esta botijuela difiere de las anteriores ya que es muy compacta y de color beige rosado. El cuerpo presenta una densidad homogénea con desgrasantes abundantes y predominantes en la zona de la panza, pero de pequeño tamaño como la anforeta globular. Los procesos postdeposicionales han hecho especial mella en esta pieza pues presenta abundantes concreciones y costras de mortero también en el exterior, algunos desconchados, la base rota, junto a la abundancia de líquenes y manchas de color negruzco, resultado de haber sido colocada la pieza en un lugar húmedo y probablemente poco iluminado. No se ha podido observar el interior. Además, ha sido rellenado con mortero de una mayor porosidad y grosor de texturas que la pasta cerámica (alcanzando los poros $27 \mathrm{~mm}$ en algún caso), asimismo no está perfectamente adherido a las superficies internas de las paredes de la botijuela, como lo muestran los huecos detectados a lo largo de las paredes que oscilan entre $3 \mathrm{y}$ $6 \mathrm{~mm}$. Este mortero demuestra un uso secundario en la arquitectura.

\subsection{Caracterización arqueométrica}

La mineralogía de la botijuela LOL02 es similar a la de la anforeta LOL01 (Tabla 2, Fig. $6)$, ambas tienen cuarzo $\left(\mathrm{SiO}_{2}\right)$ como mineral mayoritario, diópsido $\left(\mathrm{Ca}(\mathrm{Mg}, \mathrm{Al})(\mathrm{Si}, \mathrm{Al})_{2} \mathrm{O}_{6}\right)$ y gehlenita $\left(\mathrm{Ca}_{2} \mathrm{Al}_{2} \mathrm{SiO}_{7}\right)$-esta última relativamente más abundante en la botijuela LOL02. Estos dos últimos minerales se forman a partir de los productos de fusión de arcillas con materiales calcáreos, ricos en calcita y cálcico-magnésicos, ricos en dolomita. La gehlenita $\left(\mathrm{Ca}_{2} \mathrm{Al}_{2} \mathrm{SiO}_{7}\right)$ se forma a partir de los primeros bajo temperaturas de cocción de $800-900^{\circ} \mathrm{C}$ y el diópsido (Ca $\left.(\mathrm{Mg}, \mathrm{Al})(\mathrm{Si}, \mathrm{Al})_{2} \mathrm{O}_{6}\right)$ partir de los segundos (Heimann 1989) a temperaturas de $900-1000^{\circ} \mathrm{C}$. La presencia de ambos nos estaría indicando un rango de temperaturas del orden de $900-950^{\circ} \mathrm{C}$. La composición elemental de ambas botijuelas es 
similar (tabla 3), lo que apunta al uso de un mismo tipo de materia prima, la presencia en concreto de niveles relativamente altos de potasio, indica que en origen pudo haber micas $y$ feldespatos que por las temperaturas de cocción ya no se detectan.

En LOL02 se aprecia un vidriado interior, que el análisis demuestra que es plomado (Fig. 7), que además está parcialmente alterado en superficie por lixiviación del plomo. A través de la radiodensidad de las tomografías también se puede intuir la presencia de un elemento muy pesado como es el plomo. El plomo se añade como fundente para rebajar el punto de fusión de las materias primas del vidriado.

Tabla 2. Semicuantificación mineral de las pastas y relleno (HIX01m) de los recipientes analizados

\begin{tabular}{|l|l|l|l|l|l|l|l|}
\hline & Mica & Cuarzo & Calcita & Feldespato K & Plagioclasa & Diópsido & Gehlenita \\
\hline LOL01 & - & $\mathrm{xxxx}$ & - & - & - & $\mathrm{xx}$ & $\mathrm{xx}$ \\
\hline LOL02 & - & $\mathrm{xxxx}$ & - & - & $\mathrm{xx}$ & $\mathrm{xxx}$ \\
\hline HIX01 & $\operatorname{tr}$ & $\mathrm{xxxx}$ & $\mathrm{xxx}$ & $\mathrm{tr}$ & $\mathrm{tr}$ & - & - \\
\hline HIX02 & $\operatorname{tr}$ & $\mathrm{xxxx}$ & - & - & - & $\mathrm{xxx}$ & $\mathrm{xxx}$ \\
\hline HIX01m & - & $\mathrm{xxxx}$ & $\mathrm{xx}$ & $\mathrm{x}$ & $\mathrm{x}$ & - & - \\
\hline
\end{tabular}

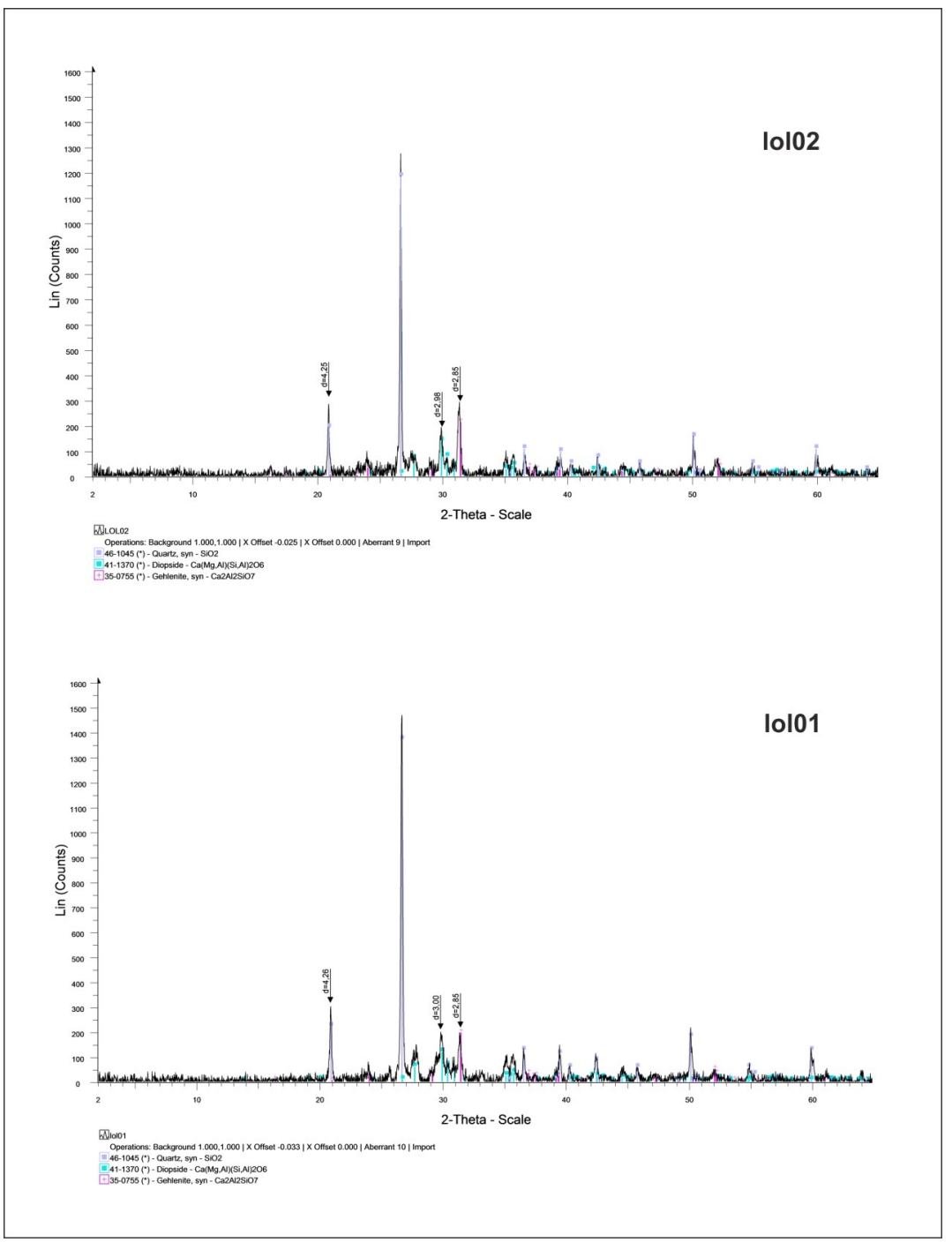

Fig. 6. Difractogramas de los cuerpos cerámicos de las botijuelas LOL02 y LOL01. 
Tabla 3. Composición elemental de las pastas de las piezas analizadas

\begin{tabular}{|c|c|c|c|c|c|c|c|c|c|c|c|c|c|c|c|c|c|c|c|c|}
\hline & Mg & Al & $\mathbf{S i}$ & $\mathrm{K}$ & $\mathrm{Ca}$ & $T$ & & $\mathrm{Fe}$ & & & & & & & & & & & & \\
\hline LOL02 & 1,5 & 5,6 & 24,1 & 2,9 & 9,4 & 0 , & & 4,2 & & & & & & & & & & & & \\
\hline LOL01 & 1,3 & 5,5 & 24,8 & 2,5 & 9,0 & 0, & & 3,7 & & & & & & & & & & & & \\
\hline HIX02 & 1,4 & 5,4 & 24,4 & 1,9 & 10, & 0 & & 3,5 & & & & & & & & & & & & \\
\hline HIX01 & 2,3 & 4,7 & 21,7 & 1,8 & 12, & 0, & & 3,0 & & & & & & & & & & & & \\
\hline HIX01m & 1,1 & 5,1 & 24,7 & 2,6 & 6,8 & 0 , & & 0,7 & & & & & & & & & & & & \\
\hline \multirow[t]{2}{*}{$\mathrm{U}$} & $\%$ & $\%$ & $\%$ & $\%$ & $\%$ & $\%$ & & $\%$ & & & & & & & & & & & & \\
\hline & $\mathbf{P}$ & $\mathbf{S}$ & $\mathrm{Cl}$ & $\mathrm{V}$ & $\mathrm{Cr}$ & $\mathrm{Ba}$ & Mn & $\mathrm{Ni}$ & $\mathrm{Cu}$ & $\mathrm{Zn}$ & $\mathrm{Ga}$ & Ge & As & $\mathrm{Se}$ & Rb & $\mathrm{Sr}$ & $\mathbf{Y}$ & $\mathrm{Zr}$ & $\mathbf{N b}$ & $\mathbf{P b}$ \\
\hline LOL02 & 162 & 1567 & 1732 & 0 & 80 & 140 & 577 & 38 & 71 & 198 & 0 & 0 & 2 & 0 & 129 & 492 & 40 & 227 & 19 & 618 \\
\hline LOL01 & 2300 & 3175 & 5521 & 70 & 42 & 313 & 957 & 45 & 29 & 175 & 0 & 0 & 11 & 0 & 123 & 439 & 29 & 213 & 17 & 238 \\
\hline HIX02 & 0 & 2274 & 4074 & 33 & 49 & 125 & 640 & 27 & 22 & 88 & 31 & 0 & 20 & 0 & 112 & 410 & 28 & 221 & 16 & 58 \\
\hline |HIX01 & 0 & 1854 & 591 & 64 & 43 & 0 & 356 & 22 & 16 & 96 & 19 & 0 & 14 & 0 & 96 & 440 & 21 & 176 & 16 & 40 \\
\hline HIX01m & 0 & 731 & 444 & 39 & 4 & 327 & 162 & 7 & 7 & 25 & 8 & 0 & 3 & 0 & 128 & 112 & 9 & 51 & 6 & 30 \\
\hline $\mathbf{U}$ & ppm & ppm & ppm & ppm & ppm & ppm & ppm & n ppm & ppm & ppm & ppm & ppm & ppm & ppm & ppm & ppm & ppm & ppm & ppm & ppm \\
\hline
\end{tabular}

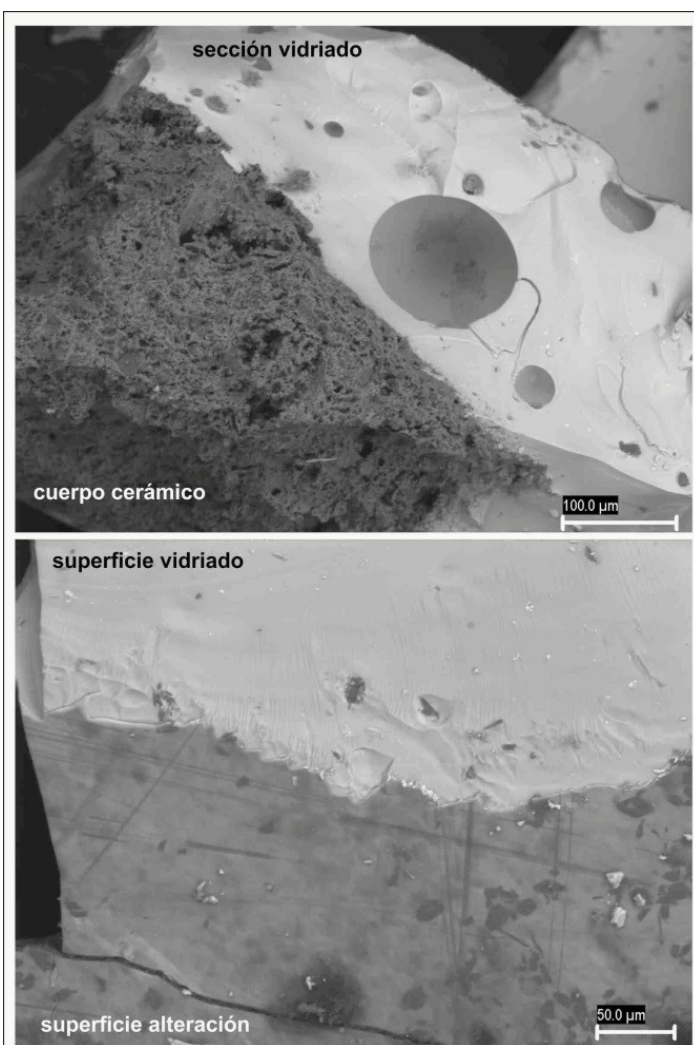

\begin{tabular}{|c|c|c|c|c|c|c|c|c|}
\hline \multirow[b]{4}{*}{0} & \multirow{2}{*}{\multicolumn{2}{|c|}{$\begin{array}{l}\text { cuerpo cerámico } \\
101002-01(1.2 .3)\end{array}$}} & \multirow{2}{*}{\multicolumn{2}{|c|}{$\frac{\text { seccion vidriado }}{\text { LOLO02-01 }(4,5,6)}$}} & \multicolumn{4}{|c|}{ superficie vidriado superficie alteración } \\
\hline & & & & & \multirow{2}{*}{\multicolumn{2}{|c|}{ LOLO02-02 $(4,5,6)$}} & \multicolumn{2}{|c|}{ LOLO02-02 $(1,2,3)$} \\
\hline & \multicolumn{2}{|c|}{$\mathrm{m} \quad \mathrm{dt}$} & \multicolumn{2}{|c|}{$\mathrm{m} \quad \mathrm{dt}$} & & & $\mathrm{m}$ & $\mathrm{dt}$ \\
\hline & 49,1 & 1,65 & 37,8 & 6,49 & 42,7 & 0,43 & 50,4 & 0,96 \\
\hline $\mathrm{Na}$ & 0,6 & 0,02 & 0,9 & 0,20 & 0,9 & 0,03 & 0,9 & 0,03 \\
\hline Mg & 2,4 & 0,29 & 0,5 & 0,33 & 0,2 & & 0,2 & 0,04 \\
\hline Al & 5,5 & 0,42 & 1,8 & 1,10 & 1,2 & 0,09 & 2,7 & 0,10 \\
\hline Si & 17,8 & 1,90 & 23,8 & 2,98 & 26,3 & 0,37 & 26,3 & 0,28 \\
\hline $\mathbf{s}$ & 0,4 & 0,07 & & & & & & \\
\hline $\mathrm{Cl}$ & & & & & & & 0,4 & 0,01 \\
\hline $\mathbf{K}$ & 0,8 & 0,13 & 4,3 & 1,01 & 4,1 & 0,05 & 4,0 & 0,07 \\
\hline $\mathrm{Ca}$ & 18,7 & 3,51 & 5,2 & 4,46 & 1,5 & 0,08 & 1,0 & 0,07 \\
\hline $\mathrm{Ti}$ & 0,3 & 0,06 & & & & & & \\
\hline $\mathbf{F e}$ & 3,9 & 0,63 & 0,9 & 0,71 & 0,3 & 0,00 & 0,5 & 0,09 \\
\hline Pb & 0,7 & 0,01 & 25,0 & 9,04 & 23,1 & 0,71 & 13,6 & 0,70 \\
\hline
\end{tabular}

Fig. 7. Micromorfología y composición elemental del vidriado de LOLO02.
La anforeta HIX02 está compuesta de cuarzo, y se identifican en abundancia igualmente los minerales de alta temperatura diópsido y gehlenita. También se detectan trazas de mica moscovita. Los niveles de potasio son relativamente más bajos que los de las muestras LOL01 y 02 , lo que indicaría que en origen esta cerámica tendría menos moscovita y feldespato potásico. La temperatura de cocción sería similar a las anteriores piezas, entre 900 y $950^{\circ} \mathrm{C}$, pero es posible que esta durase algo más de tiempo en esta temperatura de equilibrio de los dos minerales, puesto que ambos se presentan en mayor concentración. El análisis elemental (Tabla 3, Fig. 8) desvela una composición muy similar a las dos piezas anteriores, si bien tiene un contenido relativamente inferior en potasio, zinc y plomo y relativamente superior en calcio.

La anforeta HIX01 tiene una mineralogía predominante de cuarzo con calcita también muy abundante y trazas de mica moscovita, feldespato potásico y plagioclasa. La ausencia de minerales indicadores de alta temperatura, así como la presencia de la calcita, confirmarían una temperatura de cocción inferior o próxima a los $850^{\circ} \mathrm{C}$. La composición elemental (Tabla 3, Fig. 9) es prácticamente similar a la de HIX02, salvo por ser ligeramente más rica en magnesio y calcio y algo más pobre en silicio. A pesar de tener más magnesio y calcio no se llegaron a formar diópsido y gehlenita, lo que confirmaría temperaturas de cocción próximas o inferiores a los $850^{\circ} \mathrm{C}$.

El relleno de esta anforeta, tienen una mineralogía de cuarzo, calcita, feldespato potásico (microclina) y albita. Esta composición mineralógica, y elemental es la habitual en un mortero de cal con árido granítico. No se identifican fases características de cementos, constatando el uso de un mortero tradicional (Moropoulos et al. 1999).

\section{DISCUSIÓN}

En definitiva, nos encontramos con cuatro botijuelas que presentan unos rasgos cerámicos 
Cuatro 'Botijuelas' recuperadas en el Noroeste de Iberia. Procesos de manufactura y reutilización

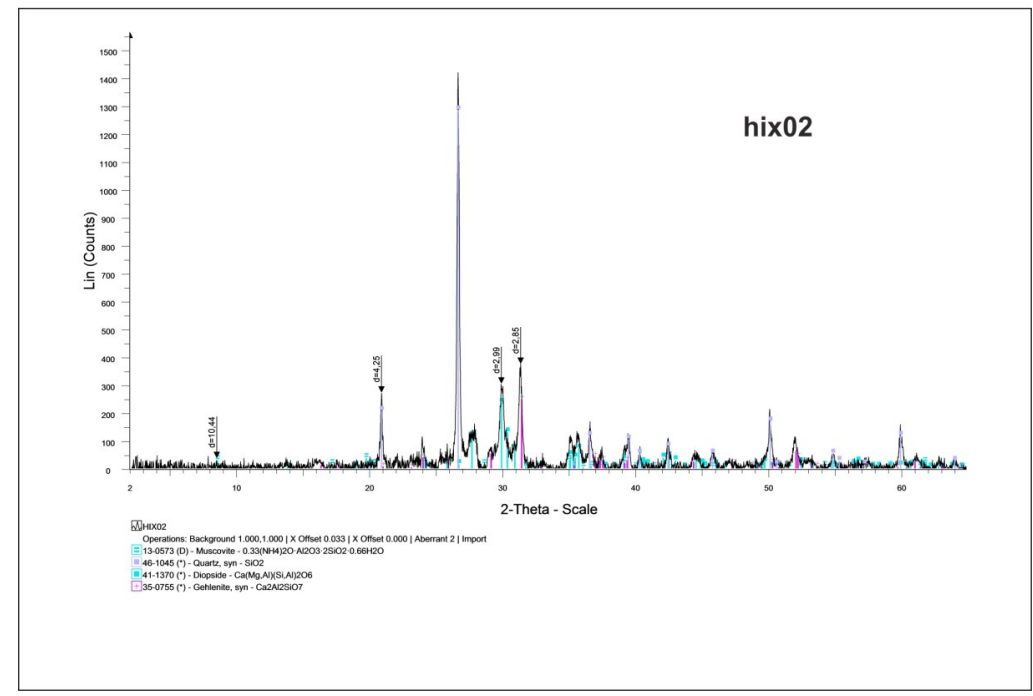

Fig. 8. Difractograma del cuerpo cerámico de HIX02.

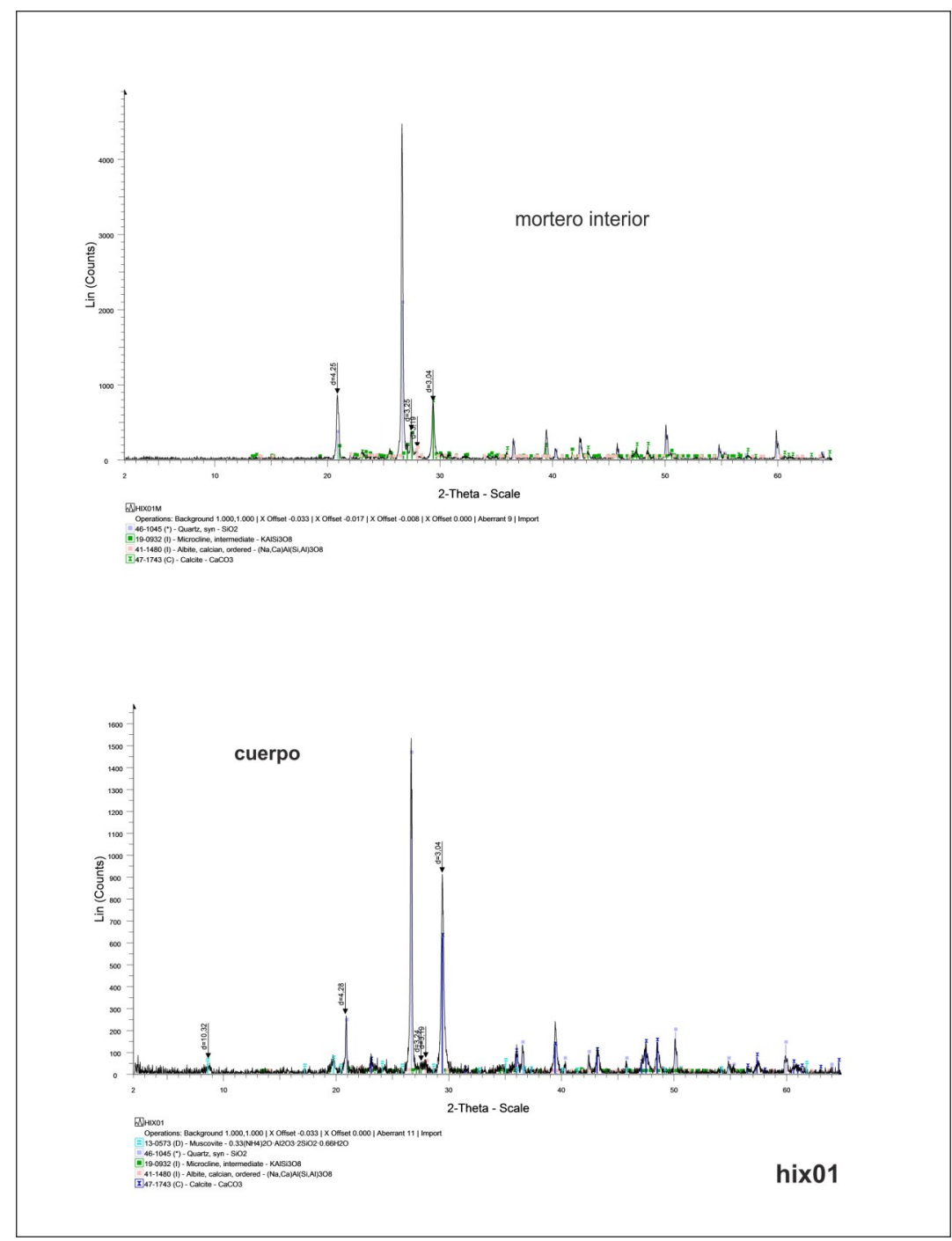

Fig. 9. Difractogramas del cuerpo cerámico y del relleno de HIX01. 
aparentemente coincidentes con la tipología del estilo tardío, de Goggin (1960), a partir de finales del siglo XVII para las botijuelas piriformes. Si tratamos de considerar otros rasgos de las vasijas, en el caso de la botijuela globular, la morfología general es coincidente con las que Marken (1994) presenta en sus botijuelas de 1621, pero además posee un sello en el hombro, propio del tercer cuarto del siglo XVIII, que por tanto retrasaría su cronología hasta la centuria de 1700 (CARROUTHERS 2003). Es difícil de determinar la antigüedad de la vasija al no disponer de un contexto arqueológico bien definido, este tipo es una de las 'formas oficiales' documentadas en grandes cantidades en los pecios de la Armada española (MARTIN 1979). Estas fueron jarras de media arroba, globulares, que pueden haber sido más fáciles de hacer con una capacidad estandarizada (CARTER 1982). Las botijuelas piriformes propiamente dichas no vienen registradas por Marken en su tipología, en la que las formas fusiformes aparecen más tardíamente. Estas botijuelas son idénticas a las encontradas en otros puntos de Asturias, cuya cronología podría ser de inicios del siglo XIX o quizás anterior, aunque no se puede concretar (DíAz 2016: 252). Quizás deba plantearse por el momento una larga perduración de las mismas (BENITO 1987).

Desde un punto de vista de reconstrucción de la cadena operativa pueden destacarse varias de las fases de la misma:

En relación con la preparación de la materia prima: seleccionada muy decantada, en general es compacta fina a través de un estudio de visu, pero gracias a la tomografía se detectan abundantes poros internos que, aunque mayoritariamente sean de pequeño tamaño y distribución regular, en algún caso se detectan algunos de gran tamaño alargados en la zona de la panza de las anforetas piriformes. La arqueometría permite definir una composición elemental muy similar para los cuatro recipientes, y también mineralógica, con la excepción de HIX01 que difiere en la ausencia de minerales de alta temperatura. Las pastas son pues muy similares y de una naturaleza arcilloso-dolomítica-calcárea. Se realizó una comparación con cerámica mayólica de diversos puntos de la península (GARCía IÑAÑEZ et al. 2008) y se comprobó como las pastas de estas botijuelas eran muy similares en composición química a las de Sevilla (de 15 elementos comparados, 9, As, Cr, Fe, Sr, Al, Ba, K, Mn y V coinciden mientras que otros cuatro $\mathrm{Zn}, \mathrm{Zr}$, Ca y Ti son ligeramente inferiores y otros dos, $\mathrm{Rb}$ y Ni son ligeramente inferiores, si bien en cualquier caso con valores relativamente próximos). En Gómez Ferrer et al. (2013) analizan olive jars de Sevilla, y también encontramos una coincidencia en las composiciones de su trabajo con las nuestras para 12 elementos (Mg, Si, K, Ti, V, Cr, Mn, Ba, Fe, Ni, Zn, Sr, Zr y $\mathrm{Nb}$ ) y tan solo diferencias no muy destacables para el Na, $\mathrm{Al}$ y Ca y en las mineralogías con gehlenita y diópsido. Complementariamente, en el análisis de arcillas de la cuenca del Guadalquivir (Cartuja, Monzanilla y Galapagar) que analiza Avery (1997), comprobamos como estas materias primas son compatibles con las que estimamos para nuestras pastas y difieren significativamente en composición y pastas de las producciones locales portuguesas (CosteIRA DA Silva 2018). No se puede asegurar certeramente un origen en estos recipientes en las materias primas sevillanas, pero los datos de los que se dispone hasta ese momento apuntan hacia esa línea. A partir de 1765 podrían existir otros talleres alejados de la producción bética, que quedan pendientes de definir por el momento, e incluso localizados en el continente americano, sin embargo las composiciones de algunas de estas piezas locales, como las de Panamá, no tienen una naturaleza calcárea como las de Sevilla y las analizadas en este trabajo (FERRER et al. 2015), al igual que se ha verificado su origen sevillano en otras piezas analizadas en contextos mejicanos (Velasquez \& Salgado-Ceballos 2016).

El modelado de las cuatro piezas, hecho a torno rápido, muestra probablemente una fabricación en dos bloques como sugirió Goggin (1960) con una juntura en el hombro. Esto tiene lógica pues el tamaño de las piezas es grande, su forma sinuosa y su arcilla cocida es pesada como para poder ser fabricada en una única pieza.

En relación con la cocción, se observa que el ambiente es oxidante, pues en materiales calcáreos con presencia de hierro da colores rosáceos y pardos como los de nuestras pastas (CAPEL et al. 1985). Las temperaturas han debido de alcanzar los $900-950^{\circ} \mathrm{C}$, indicadas por la presencia de gehlenita y diópsido, siendo coherente con las temperaturas encontradas para olive jars sevillanas en el trabajo de Gómez Ferrer et al. (2013). Si bien en HIX01, no se han alcanzado los $850{ }^{\circ} \mathrm{C}$ puesto que están ausentes estos dos minerales y además se detecta calcita, un mineral que comienza a destruirse sobre los $800^{\circ} \mathrm{C}$ (Heimman 1989). Si bien la composición indica un origen similar a nivel geológico, para los cuatro recipientes, la cronología de los mismos puede ser muy dispar, influyendo tal vez este hecho, en las temperaturas de cocción.

Finalmente, si consideramos la función primaria de las piezas, teniendo en cuenta la morfología combinada con pastas adecuadas, tamaño y presencia o no de vidriado nos permite aproximar una primera función en las botijuelas, la globular posiblemente usada para vino o licor, las piriformes, para elementos semisólidos como miel o más densos como aceite (AZKÁRATE \& NúÑEZ 1991). Un análisis de contenidos podría ser interesante si hubiesen sido encontradas en contextos arqueológicos.

\section{CONCLUSIONES}

A pesar de no conocer el contexto de procedencia de las piezas, los estudios analíticos de las mismas nos han permitido no sólo definir características de producción de las piezas sino también algunos aspectos de sus usos secundarios. Dada su procedencia en mercados de coleccionismo asturianos y gallegos, quizás provengan de algún pecio allí documentado, como el de Ribadeo, para el que hay constancia de que en las playas limítrofes se encontraban recipientes y en las prospecciones subacuáticas se confirmó la presencia de anforetas y botijuetas. Las anforetas piriformes muestran una 
gran similitud tipológica con aquellas documentadas en Asturias, y cuyo tamaño y capacidad podría coincidir con un uso primario de transporte de aceite, su tamaño (1 litro y 1,5 litro de capacidad) y pastas así lo podrían sugerir. La botijuela globular, de mayor tamaño, con casi 6 litros de capacidad, vidriada podría estar destinada al transporte de licores o vino, pieza que, aunque en este conjunto sea única, responde a una manufactura oficial, estandarizada en las producciones de anforetas de indias. Aunque no se puede realizar un seguimiento completo de la biografía de las botijuelas, y no se puede descartar para alguna pieza una importación a través del intercambio del coleccionismo, la abundancia de este tipo de recipientes en elementos arquitectónicos de la costa de Lugo y de Asturias, la presencia de pecios con este tipo de carga en las costas próximas y la información recabada a sus propietarios sobre la movilidad reciente de las piezas, apuntan a que su llegada a estos territorios podría haber sido en una fase de uso, como transporte en barcos que se hundieron en las proximidades y no como resultado de actividades comerciales vinculadas al coleccionismo reciente en la zona.

Cabe destacar que es sorprendente la similitud que tienen estos cuatro recipientes en su composición química, pudiendo evidanciar quizás una procedencia de un mismo lote cerámico. En concreto, esta similitud se agranda entre los pares HIX01-HIX02 y LOL01-LOL02. En cuanto a la mineralogía, la botijuela piriforme LOL01 y la botijuela globular LOL02 son totalmente similares. La botijuela piriforme HIX02 también es similar a este conjunto, aunque se detectan trazas de micas, e HIX01 siendo igual composicionalmente al conjunto estudiado difiere únicamente desde un punto de vista tecnológico, puesto que ha sido cocida a temperaturas inferiores al resto de recipientes (del orden de 800 a $850^{\circ} \mathrm{C}$ ). Esta misma botijuela está rellena de un mortero tradicional que evidencia una reutilización como elemento decorativo arquitectónico, frecuente en el norte de Galicia y Asturias. En cuanto al origen de las materias primas de las pastas, descartamos que tengan su origen en Galicia, debido a su caracter margoso-calcáreo y apuntamos a un origen hacia el sur de la Península, en concreto en zonas de materias primas arcillosas de la cuenca del Guadalquivir que también se utilizaron en la elaboración de cerámica medieval sevillana. Son necesarias más comparaciones para confirmar con seguridad esta hipótesis.

En definitiva, estas botijuelas han llegado a nuestros días gracias a que fueron reutilizadas para otros usos, usos secundarios como elementos arquitectónicos (Fig. 10) y sin relación con la producción original, complementariamente pasando a formar parte de colecciones cerámicas. Es de gran interés, por lo tanto, averiguar aspectos sobre la producción de estas piezas, pues aportan información concreta sobre las vasijas y la tecnología de producción y consumo de su época. También es importante conocer su historia vital hasta la actualidad, pues quizás nos permita conocer mejor la sociedad rural en la que han sido reutilizadas posteriormente y la tradición constructiva de estas áreas costeras gallegas y asturianas.

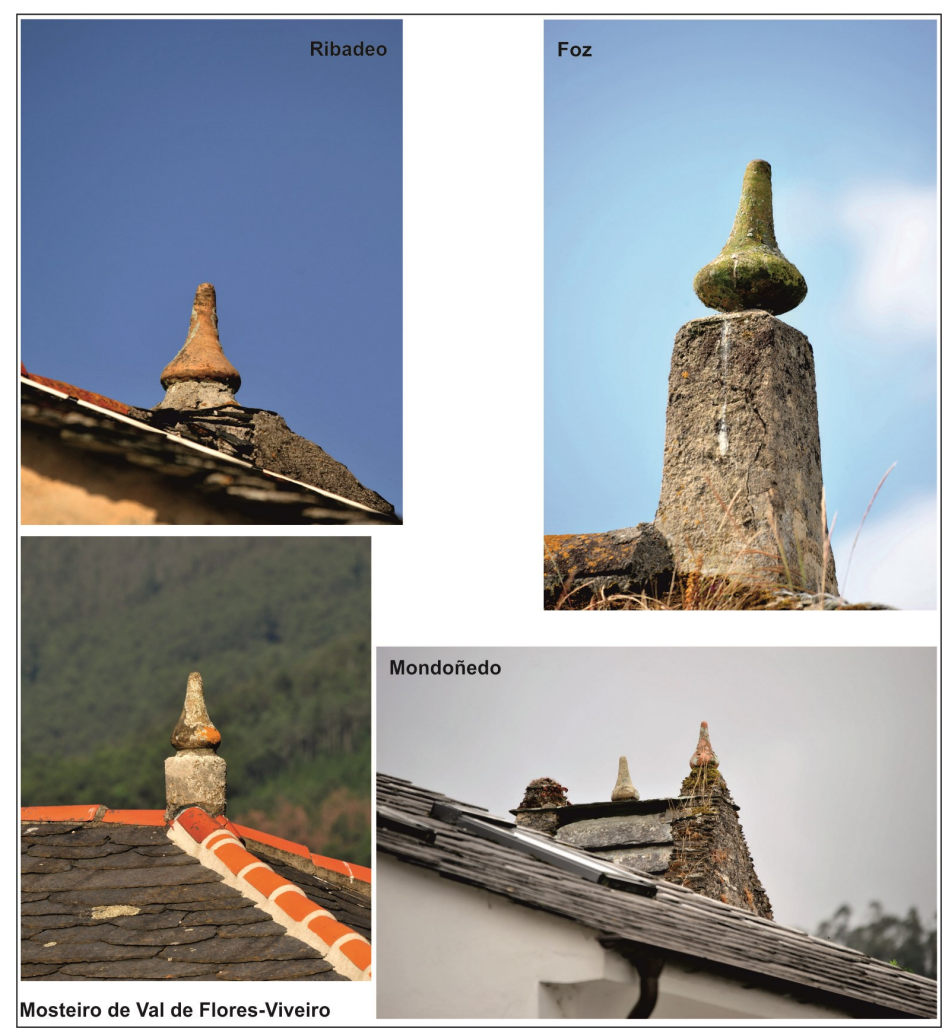

Fig. 10. Selección de algunas piezas piriformes documentadas en la actualizad en tejados de casas del norte de Lugo (fotografía: L. Hixinio Flores Rivas). 


\section{Reconocimientos}

Este trabajo ha sido desarrollado en el marco de dos proyectos. "Tecnología y producción de la cerámica medieval de Galicia" (MC-PTG). HAR2015-64441-P (Plan Nacional: Ministerio de Economía y Competitividad, Convocatorias 2015, Proyectos EXCELENCIA y Proyectos RETOS, Dirección General de Investigación Científica y Técnica, Subdirección General de Proyectos de Investigación), 20162019 y parcialmente financiado dentro de las actividades de divulgación científica y de promoción científica de la Red de Infraestructuras de Apoio á Investigación e ao Desenvolvemento Tecnolóxico (RIAIDT, USC). Una parte del trabajo de MPPM fue desarrollada como investigadora invitada en la Université de Montreal con el proyecto código PRX18/00408 de ayudas dentro del programa de estancias del Programa 'Salvador Madariaga' (2018-2019) del Ministerio de Ciencia, Innovación y Universidades del Gobierno de España.

Asimismo agradecemos los comentarios y recomendaciones de los revisores anónimos realizados al trabajo, que han permitido mejorar este texto.

\section{BIBLIOGRAFÍA}

Avery, G. 1997. Pots as packaging: The Spanish olive jar and Andalusian transatlantic commercial activity, 16th-18th centuries. Dissertation Thesis, Universidad de Florida.

Azkárate Garai-Olaun, A. \& NúÑez Marcén, J. 19901991 Colección de Botijas y Botijuelas ("Spanish Olive Jar" o "Anforetas") procedentes de la Ermita de San José (Elorrio, Bizkaia). Kobie (Serie Paleoantropología), 19: 153-182.

BARTON, K.J. 1977. Coarse Earthenwares from the Fortress of Louisbourg. Nova Scotia, Typescript.

Benito Domínguez, A.M. 1987. Anforetas y botijuelas halladas en Guipuzcua. Munibe, 39: 139-145.

Capel, J.; Huertas, F. \& Linares, J. 1985. High Temperature Reactions and use of Bronze Age Pottery from La Mancha, Central Spain. Mineralogical Petrographica Acta, 29: 563-575.

CARAmÉs Moreira, V. 2006. Lozas sevillanas en Baiona en los siglos XV y XVI. GLAUCOPIS Boletín do Instituto de Estudos Vigueses, 12: 203-228.

Caramés Moreira, V.; Castro Lorenzo, M.L. \& Suárez Otero, J. 2006. Cerámicas de lujo en la Galicia del siglo XV. In: Os Capitulos da Irmandade. Peregrinación y conflicto social en la Galicia del siglo XV, Santiago de Compostela, Tórculo Edicións: 200211.

Castro Lorenzo, M.L. 2006. La mayólica italiana: platos de Montelupo con decoración "Al blu grafitto" en Santiago de Compostela. Boletín Auriense, 36: 3546.

Castro Lorenzo, M.L. 2009. La vajilla de lujo en Santiago de Compostela en los siglos XVI y XVII: aportaciones de la arqueología. Revista de Estudios Provinciais, 22: 123-158.

Carter, J. 1982. Spanish Olive Jars From Fermeuse Harbour, Newfoundland. Material Culture Review Revue de la culture matérielle, 16: 99-108 (https:// journals.lib.unb.ca/index.php/MCR/article/ view/17151/22853 (Date accessed: 27 june 2018).

Carrouthers, C. 2003. Spanish Botijas or olive jars from the Santo Domingo Monastery, La Antigua Guatemala. Historical Archaeology, 37 (4): 40-55.

CÉsar Vila M. \& Bonilla Rodríguez A., 2003, Estudio de los materiales cerámicos del "Castelo da
Lúa” (Rianxo, A Coruña). Gallaecia, 22: 297-367.

Costa, B.F.O.; Silva, A.J.M.; Ramalho, A.; Pereira, G. \& Ramos Silva, M. 2011. X-ray compositional microanalysis and diffraction studies of Haltern $70 \mathrm{am}$ phorae sherds. X-ray Spectrometry. DOI 10.1002/ xrs.1379.

Costeira DA SiLVA, R. 2018. Um carrego de abóbada na igreja quinhentista de Santo António (Aveiro, Portugal). Revista Portuguesa de Arqueologia, 21: 181 -195 .

DíAZ DíAZ, V.M. 2016. Seis contenedores cerámicos de época moderna y contemporánea en el entorno de la ría del Eo. Nailos. Estudios interdisciplinares de Arqueología, 3: 241-259.

Escribano Ruiz, S. \& Barreiro Argüelles, S. 2016. Travelling ceramics: Basque networks and identities in the Gulf of Saint Lawrence. In: B. LoEweN \& C. Chapdelaine (Eds.), Contact in the 16th Century. Networks among fishers, foragers and farmers, . Québec, University of Ottawa Press: 31-55.

Escribano Cobo, G. \& Mederos Martín, A. 1998. Botijas en yacimientos arqueológicos subacuáticos de las Islas Canarias. Una fuente complementaria para el análisis del comercio canario-americano. In: F. Morales Padrón (Coord.), XII Coloquio de Historia Canario-Americana (1996), Las Palmas de Gran Canaria, Cabildo de Gran Canaria: 539-568.

Fariña, F.; Romero, M., \&VÁzquez, J.M. 1973. Nuevos hallazgos de anforiñas. El Museo de Pontevedra, 27: $72-88$.

FERRER, S.G.; BUXEDA I GARRIGÓs, J.; IÑAÑEZ, J.G. \& GLASCOCK, M.D. 2015. Local and European transport jar sin Panama. Chemical and Mineralogical characterization. In: J. BUXEDA I GARRIGós, M Madrid i Fernández \& J. García IÑañez (Eds.), Global Pottery1: historical archaeology and archaeometry for societies in contact, Oxford, BAR International Series 2761: 333-352.

García IÑañez, J.; SPeakman R.J., Buxeda I Garrigós, J. \& GLASCOCK, M.D. 2008. Chemical characterization of majolica from 14the18th century production centers on the Iberian Peninsula: a preliminary neutron activation study. Journal of Archaeological Science, 35: 425-440.

GoGgIN, J.M. 1960. The Spanish Olive Jar: An Introductory Study. New Haven, Yale University .

Gómez Ferrer, S.; BuXxeda I Garrigós, J.; García IÑañez, J.; De Amores Carredano, F. \& Alzate Gallego, A. 2013. Sevillian transport jars in early colonian America: the case of Santa María La Antigua del Darién (Colombia). Open Journal of Archaeometry, 1(e3): 10-15.

HeimanN, R.B. 1989. Assesing the technology of ancient pottery: the use of ceramic phase diagrams. Archaeomaterials, 3(2): 123-148.

KaWAGUCHI, Y. 2011. The newly found olive jars in Japan and their historical significance. Sokendai Review of Cultural and Social Studies, 7: 123-132.

Lantes-Suárez, O., Doval Galán, J.F. \& Prieto MARTínez, M.P. 2016. La alfarería tradicional de Buño. Una aproximación desde la arqueología y la arqueometría. Gallaecia, 35: 175-223.

LANTES-SuÁREZ, O. 2018. Arqueometría da cerámica popular de Samos. En: L.H. Flores Rivas \& O. Viveiro Veiga (Eds.) Formas tradicionais da cerámica popular: SAMOS. Lugo, Centro de Artesanía e Deseño, Deputación de Lugo: 280-311. 
Lantes Suarez, O. \& Prieto Martínez, M. P. 2017a. Técnicas de imagen de rayos $\mathrm{X}$ y arqueología. Estado de la cuestión y potencialidad de la técnica. Antrope, $7:$ 14-36.

Lantes Suarez, O. \& Prieto Martínez, M. P. 2017b. Primeras aplicaciones arqueológicas y museísticas en Galicia de tomografía computerizada de rayos X. $O$ Ideario Patrimonial, 9: 5-35.

Lantes-SuÁrez, O.; Prieto-Martínez, M.P. \& MartínezCortizas, A. 2011. Aplicación de la Microscopía Electrónica de Barrido al estudio de los acabados de cerámica antigua de Galicia. Gallaecia, 30: 117 125 .

Lister, F.C. \& Lister, R.H. 1979. A Descriptive Dictionary for 500 Years of Spanish-Tradition Ceramics (13th through 18th centuries). Special Publication Series No. 1. Washington, D.C.: Society for Historical Archaeology.

LóPEz Gómez, F.S. 1980. Arqueoloxia sobmariña: os materiais procedentes da badia coruñesa Brigantium, I: 139-165.

Loureiro V. \& Martinho C. 2007. As anforetas do Cabo Sardâo. O Arqueólogo Português, Série IV (25): 373-408.

MartiN, C.J.M. 1979. Spanish Armada Pottery. International Journal of Nautical Archaeology, 8 : 279-302.

Marken, M.W. 1994. Pottery from Spanish Shipwrecks 1500-1800. Gainesville: University Press of Florida.

Martínez CaSAL J.R. 2006. A cerámica medieval da fortaleza de A Rocha Forte. Contribución ao seu estudo. Gallaecia, 25: 187-225.

Martínez Casal, J.R. 2007. Estudio del material ergológico: Cerámica. In: Moeche, Fortaleza- Museo del siglo. XXI A Coruña, Concello de Moeche: 89-116.

Martínez Peñín, R. 2013. Los estudios de cerámica medieval en el noroeste peninsular: Galicia y norte de Portugal. Interconexões - Revista de Ciências Sociais, 1(1): 33-60.

Moropoulou, A.; Bakolas, A. \& Bisbikou, K. 1999. Investigation of the technology of historic mortars. Journal of Cultural Heritage, 1: 45-48.

Peacock, D.P.S. \& Williams, D.F. 1986. Amphorae and the Roman economy. An introductory guide. London, Longman.

Pleguezuelo, A. \& Lafuente, M.P. 1995. Cerámicas de Andalucía Occidental (1200-1600). In: C.M. GERrard, A. Gutiérrez \& A.G. Vince (Eds.), Spanish Medieval Ceramics in Spain and the British Isles: Cerámica medieval española en España y en las Islas Británicas. Oxford: Archaeopress - BAR International Series; 610: 217-244.
Prieto-Martínez M.P. 2007. Volviendo a un mismo lugar: recipientes y espacios en un monumento megalítico gallego (NW de España). Revista Portuguesa de Arqueología, 10 (2): 101-125.

Prieto Martínez, M.P.; Lantes Suárez, O. \& Alonso Toucido, A. 2015.Una cerámica de gres de Raeren en Santiago de Compostela (NW Spain). In: R. Martínez PeÑín \& G. Cavero Domínguez (Eds.) Evolución de los espacios urbanos y sus territorios en el Noroeste de la Península Ibérica, León, Universidad de León - Instituto de Estudios Medievales: 253-268.

Prieto Martínez, M.P.; Lantes Suárez, O.; VÁzouez Liz, P. \& Martínez Cortizas, A. 2010, La cerámica de dos túmulos de Roza das Aveas (Outeiro de Rei, Lugo): Un estudio diacrónico del estilo y la composición. BSAA arqueología, 76: 27-62.

Prieto-Martínez M.P.; Lantes-Suárez O.; Alonso TouCIDO, F. 2017. La cerámica vidriada de A Pousada (Santiago de Compostela): un estudio tecnológico y arqueométrico. Gallaecia, 36: 183-195. http:// dx.doi.org/10.15304/gall.36.5137.

Prieto-Martínez M.P.; Lantes-SuÁrez O.,;Alonso TouCIDO, F. 2018. Contribución de la arqueometría a la caracterización de la cerámica medieval en Galicia. Arqueología medieval, 12: 79-110.

San Claudio Santa Cruz, M.; González Gallero, R.; Casabán Banaclocha, J. L.; Castro, F. \& DomínGUEZ Delmás, M. 2014. El pecio de Ribadeo, un excepcionalmente bien conservado pecio español del siglo XVI. In: F.X. Nieto Prieto \& M. BeteNCOURT NúÑEZ (Coords.), Arqueología subacuática española: Actas del I Congreso de Arqueología Naútica y Subacuática Española, Cartagena, 14, 15 y 16 de marzo de 2013. Cartagena, UCA Editores: 169-178.

SuÁrez Otero, J. 1993. Cerámica levantina en el comercio atlántico bajomedieval: una primera aproximación a sus manifestaciones en el ámbito gallego. Boletín Auriense, XXIII: 89-99.

Velasquez, V. \& Salgado-Ceballos, C. 2016. Spanish olive jars in Campeche: Preliminary chemical characterization and provenance identification of early modern transport vessels in the Yucatán Peninsula (Mexico) Journal of Archaeological Science: Reports, 21: 1171-1180. DOI: 10.1016/ j.jasrep.2016.10.007

WatkIns, C.M. 1972. Ceramics Used in America: Comparisons. In: I.M.G. Quimby $(E d$. $)$, Ceramics in America, Charlottesville, University Press of Virginia: 191-96. 